\title{
Freshly squeezed: anaphylaxis caused by drone larvae juice
}

Department of Dermatology, Venereology, and Allergology, University Hospital Würzburg, Würzburg, Germany

\section{KEY WORDS}

venom; honey; royal jelly; propolis;

beekeeping

\section{Corresponding author}

Johanna Stoevesandt

Department of Dermatology, Venereology,

and Allergology

University Hospital Würzburg

Josef-Schneider-Straße 2

97080 Würzburg, Germany

Phone: +49(0)93120126726

Fax: +49(0)93120126026

E-mail: Stoevesandt_J@ukw.de

Doi

10.23822/EurAnnACI.1764-1489.43

\begin{abstract}
Summary
Drone larvae are mostly considered a by-product of beekeeping, but have recently been advocated as a high-protein source of food. There are as yet no data concerning their allergenic potential.

We report on a 29-year old bee keeper who experienced an anaphylactic reaction following the consumption of a freshly prepared beverage from raw drone larvae. Larvae-specific sensitization was confirmed by prick-to-prick and basophil activation testing. Bee stings and classical bee products including honey and royal jelly were tolerated.

This is the hitherto first report on IgE-mediated allergy to drone larvae. We suggest that a certain awareness towards the allergenicity of bee larvae is required.
\end{abstract}

\section{Introduction}

Drone larvae are commonly considered a by-product of beekeeping to be removed from the colonies for the management of Varroa mites (1). Other than honey, royal jelly, and propolis, larvae are not normally consumed in Western countries, though they have been advocated as a high-protein source of food (2). Strengthening and invigorating properties have been attributed to drone brood preparations, also referred to as "apilarnil", a homogenized mixture of male larvae, royal jelly, and residual brood combs.

\section{Case presentation}

A 29-year-old beekeeper prepared a raw drone brood juice by putting entire combs in a conventional juicer and took a small sip.
He immediately experienced an itching sensation in his mouth and ears which spontaneously subsided. Some 60 minutes later, he developed a systemic anaphylactic reaction including flush and angioedema, cough, respiratory distress, nausea, vomiting, and tachycardia. He received intravenous emergency treatment with antihistamines and steroids, and was admitted to hospital for further observation. He had a history of mild allergic rhinitis and asthma, but never had asthma exacerbations while beekeeping. During the past two years, he had had about 20 bee stings and occasionally suffered from large local reactions, but never experienced sting-induced anaphylaxis. He was eating honey on a daily basis and had occasionally consumed royal jelly and propolis without symptoms. This was his first deliberate consumption of larvae. Total and bee/Vespula venom-specific IgE were measured using the ImmunoCAP method (Thermo Fisher Scientific, Freiburg, 
Germany). Basophil activation testing was done with honey bee venom $(1.0-0.001 \mu \mathrm{g} / \mathrm{ml})$ and the supernatant of the culprit drone brood juice after centrifugation (pure and aqueous dilutions ranging from 1:5 to 1:100,000). Activated basophils (i.e. CD63 and IgE double positive cells) were measured by flow cytometry. Intradermal tests with bee/Vespula venom and prickto-prick tests with a variety of bee products (drone brood juice, raw and cooked larvae, royal jelly, honey, beeswax, and propolis) were performed according to international standards, with reading after 15 minutes. Our patient was serologically sensitized to honey bee venom (total $\mathrm{IgE} 313 \mathrm{kU} / \mathrm{L}$, bee venom-specific $\operatorname{IgE} 2.99 \mathrm{kU} / \mathrm{L}$, IgE to rApi m1 $0.99 \mathrm{kU} / \mathrm{L}$ ) and had a positive intradermal test response to bee venom at $0.1 \mu \mathrm{g} / \mathrm{L}$. Honey bee venom basophil activation tests, however, were negative. Prickto-prick-tests with drone brood juice and raw larvae were clearly positive with wheals sized 10 and $6 \mathrm{~mm}$, respectively (histamine positive control $5 \mathrm{~mm})$. A smaller wheal $(3 \mathrm{~mm})$ was obtained when using a cooked larva (microwave, 45 seconds, $600 \mathrm{~W}$ ). Basophil activation tests using centrifuged drone brood juice were positive with a maximum activation rate of $89.1 \%$ at a dilution of 1:100 (negative control $1.75 \%$, positive control $50.5 \%)$. Prick-to-prick tests with all other bee products were negative, and oral provocation with a teaspoon of royal jelly was tolerated without symptoms. The patient was advised to avoid all preparations openly containing bee larvae and to exercise extreme caution when consuming other bee products potentially contaminated with larvae protein.

\section{Discussion}

To our knowledge, this is the hitherto first report on IgE-mediated allergy to bee larvae. Continued tolerance of honey and royal jelly and negative skin test reactivity to propolis and beeswax were suggestive of a larvae-specific sensitization. Mode and route of sensitization are open to speculation, but several aspects are worth discussion. 1) Honey bee venom allergy as the primary source of sensitization and subsequent cross-reactivity to larvae proteins was considered unlikely as the patient had never experienced anaphylactic sting reactions, and basophil activation tests with incremental doses of bee venom were invariably negative despite serological and skin test reactivity to honey bee venom. 2) Though the patient had never before deliberately consumed larvae, oral sensitization was considered an option as he might have accidently ingested residuals of larvae when harvesting royal jelly from the brood coombs. 3) In view of the patient's atopic condition, inhalation of dust particles containing larvae and/or bee body components while beekeeping was likewise assumed to be a plausible source of sensitization. Interestingly, he described mucosal itching resembling oral allergy syndrome as the first symptom of the allergic reaction, and prick tests with cooked larvae were suggestive of a certain heat-lability of the causative allergen.

The above mentioned considerations are in accordance with reports on IgE-mediated allergy to other bee-products identifying beekeeping, atopy and respiratory diseases as risk factors, whereas clinically relevant cross-reactivity to honey bee venom seems to be an exception (3). Royal jelly is a glandular secretion from worker bees used to feed all kinds of larvae and the adult queen. Royal jelly-induced anaphylaxis has been described on several occasions and may take a severe or even fatal course (4-6). Due to local nutritional habits, it is considered to be more prevalent in Asia (7). Of note, one of the above mentioned case reports does not specify the exact composition of the culprit royal jelly preparation referred to as "beverage containing crude royal jelly" (4), therefore giving rise to the question whether contaminating larvae might have been the actual elicitor of anaphylaxis. Major royal jelly proteins 8 and 9 have been identified as glycosylated components of bee venom (Api m11), whereas their clinical relevance for sting-induced anaphylactic reactions remains uncertain $(3,8)$. Furthermore, royal jelly has been recognized as a cause of occupational allergic respiratory disease (9). Honey is a sporadic elicitor of immediate-type allergic reactions which may range from oral allergy syndrome to severe anaphylaxis, and have been attributed to residual bee secretions, body parts, and/or pollen proteins (10). Propolis, a resinous mixture used as a sealant, represents a frequently recognized contact allergen rather than an elicitor of anaphylaxis (3).

\section{Conclusion}

Larvae ought to be added to the list of potentially allergenic bee products. Our observations are unlikely to alter current dietary habits in Western countries as most people would abstain from the consumption of larvae due to disgust rather than for the fear of allergy. They might, however, be of global interest as eating insects is a common practice in many developing countries (2).

\section{Conflict of interest}

The authors declare that they have no conflict of interest.

\section{References}

1. Rosenkranz P, Aumeier P, Ziegelmann B. Biology and control of Varroa destructor. J Invertebr Pathol 2010; 103Suppl1:S96-119.

2. Bruun Jensen A, Evans J, Jonas-Levi A, Benjamin O, Martinez I, Dahle B, Roos N, Lecocq A, Foley K. Standard methods for Apis mellifera brood as human food. J Apicultural Research 2016; DOI :10.1080/00218839.2016.1226606.

3. Cifuentes L. Allergy to honeybee ... not only stings. Curr Opin Allergy Clin Immunol 2015; 15:364-8.

4. Katayama M, Aoki M, Kawana S. Case of anaphylaxis caused by ingestion of royal jelly. J Dermatol 2008; 35:222-4. 
5. Takahama H, Shimazu T. Food-induced anaphylaxis caused by ingestion of royal jelly. J Dermatol 2006; 33:424-6.

6. Bullock RJ, Rohan A, Straatmans JA. Fatal royal jelly-induced asthma. Med J Aust 1994; 160:44.

7. Lee BW, Shek LP, Gerez IF, Soh SE, Van Bever HP. Food allergy-lessons from Asia. World Allergy Organ J 2008; 1:129-33.

8. Blank S, Bantleon FI, McIntyre M, Ollert M, Spillner E. The major royal jelly proteins 8 and 9 (Api m 11) are glycosylated components of Apis mellifera venom with allergenic potential beyond carbohydrate-based reactivity. Clin Exp Allergy 2012; 42:976-85.

9. Gómez Torrijos E, Méndez Diaz Y, Borja Segade JM, Feo Brito JF, Alfaya Arias T, Galindo Bonilla PA, Ledesma Fernandez A, García Rodríguez R. Occupational allergic respiratory disease due to royal jelly. Ann Allergy Asthma Immunol 2016; 117:102-3.

10. Bauer L, Kohlich A, Hirschwehr R, Siemann U, Ebner H, Scheiner $\mathrm{O}, \mathrm{Kraft} \mathrm{D}$, Ebner C. Food allergy to honey: pollen or bee products? Characterization of allergenic proteins in honey by means of immunoblotting. J Allergy Clin Immunol 1996; 97:65-73. 